QUADERNS DE FILOSOFIA VOL. II NÚM. 2 (2015): 9I-3

ISSN: 234I-I4I 4 eISSN: 234I-3042 DOI: IO.7203/QFIA.2.2.707I

Josep E. Corbí

Universitat de València

\title{
El nostre lloc al món en què creiem
}

T es tres Conferències que Barry Stroud Va impartir l'any 20 i 4 en la Càtedra Filosofia i Ciutadania Josep L. Blasco recorren de manera resumida, però precisa, els passos fonamentals d'una trajectòria filosòfica centrada en la reflexió sobre la relació entre el que pensem sobre el món i el món mateix sobre el qual pensem i al qual responem d'una o altra manera. El primer pas en aquesta trajectòria podem trobar-lo en Hume (1977), ${ }^{1}$ on Stroud reconstrueix amb detall i discuteix la manera en què Hume tracta de derivar de l'experiència algunes de les idees que articulen la nostra concepció del món, com ara la idea de causalitat o connexió necessària, la del jo i la de virtut. En la primera d'aquestes conferències, Stroud assenyala els aspectes centrals d'aquest projecte amb el propòsit de mostrar-nos com descansa en una visió restringida del que ens és donat en l'experiència. Aquesta visió austera o restringida té en l'argument del somni de René Descartes un punt de partida.

Aquest argument no sols dóna lloc al desenvolupament del dubte escèptic sobre el món extern, que Stroud examina en The significance of Philosophical Scepticism (1984), ${ }^{2}$ sinó que també fomenta la convicció que el que ens és donat en l'experiència no ens posa mai en contacte directe amb el món en el qual creiem. Aquesta és precisament la lectura restringida de l'experiència a la qual al.ludia abans i que pressuposa, al seu torn, certa imatge de com s'articula la nostra concepció del món. Aquesta imatge entén que la nostra manera de concebre el món és fruit de la combinació entre el que posa el món i el que aportem nosaltres. Les ciències naturals tendeixen a fer-nos pensar que el món

${ }^{1}$ Londres: Routledge, 1977; Hume, trad. cast. de Antonio Zirión, Mèxic: UNAM-IIF, I986/2005.

${ }^{2}$ Oxford: Oxford University Press, 1984; El escepticismo filosófico y su significación, trad. cast de Leticia García Urriza, Mèxic: F.C.E., I990. 
està constituït per partícules en moviment i que la resta, ja siguen olors, sabors, judicis estètics o axiològics, ho posem nosaltres, són part de la nostra resposta a allò que el món és en si mateix, independentment de nosaltres. Arribem, d'aquesta manera, a la mateixa lectura restringida de l'experiència a què apuntava l'argument del somni: les olors, els sabors, el bo i el bell es troben només en la nostra experiència, no cal que hi haja res al món extern que tinga aquestes propietats. És per això que podem dir que aquestes propietats són subjectives.

En The Quest for Reality: Subjectivism and the Metaphysics of Colour (1999), ${ }^{3}$ Stroud es proposa mostrar la insuficiència d'un tractament subjectivista dels colors mitjançant un primmirat argument transcendental. El subjectivisme assumeix que tenim creences sobre els colors i que podem identificar el contingut d'aquestes creences a partir de les nostres sensacions de color, és a dir, del que ens és donat segons la lectura restringida de l'experiència. Stroud argumenta, però, que no podem identificar en què consisteix la sensació de groc, en contraposició amb la sensació de vermell, sense assenyalar objectes que reconeixem com a grocs $\mathrm{i}$ com a vermells $\mathrm{i}$, per tant, sense que suposem que aquest objecte és groc i aquell altre, vermell. Conclou, per això, que el subjectivisme del color no pot pensar-se coherentment, atès que no pot donar compte del contingut de les nostres creences de color sense anar més allà del que ens aporta l'experiència en la lectura austera o restringida. Que el subjectivisme dels colors no puga pensar-se coherentment, no exclou que puga ser vertader. Els arguments transcendentals sols arriben a mostrar el que hem de suposar per a poder creure el que creiem, però no poden garantir la veritat de les nostres creences ni, per tant, la veritat del que aquestes ens obliguen a suposar. Aquesta limitació afecta igualment els arguments transcendentals contra l'escepticisme: poden mostrar que el dubte escèptic no pot plantejar-se coherentment, però no poden excloure la falsedat de les creences en qüestió.

En les dues darreres conferències, com en Engagement and Metaphysical Dissatisfaction: Modality and Value (201 I), ${ }^{4}$ Stroud construeix un argument transcendental similar contra les teories subjectivistes de la bellesa, de la causalitat i dels valors. Per exemple, per reduir una condemna moral a un sentiment de desaprovació, hauríem de determinar en què consisteix aital sentiment $i$, per tant, com es distingeix d'altres sentiments de desgrat. Stroud argumenta, però, que no podem respondre a aquestes preguntes des d'una concepció restringida de l'experiència, ja que la desaprovació comporta un judici i el judici l'ús de conceptes. I els mateixos conceptes que apareixen en el judici sobre la crueltat

${ }^{3}$ Oxford: Oxford University Press, I999; La búsqueda de la realidad: el subjetivismo y la metafísica del color, trad. cast. de Jordi Valor, Madrid: Síntesis, 2003.

${ }^{4}$ Oxford: Oxford University Press, 20 I I. 
d'un acte articulen la nostra experiència de desaprovació d'aquest acte. No sembla, doncs, que puguem identificar un sentiment de desaprovació llevat que suposem que certs actes són cruels. No hi ha prou amb el fet que sapiguem que ens resulten desagradables, ja que això no ens permetria de distingir entre la crueltat $\mathrm{i}$ altres formes de desgrat $\mathrm{i}$, a més a més, quan afirmem que un acte és cruel ens comprometem amb el fet que ho és encara que no desagrade de fet a ningú, ni tan sols a un mateix. Ens acostem, d'aquesta manera, a una concepció enriquida de l'experiència que pren com a punt de partida la reflexió de Kant sobre les condicions de possibilitat de la idea d'un món objectiu que els judicis de la matemàtica i de la física pressuposen. Stroud desenvolupa aquesta línia argumentativa més enllà de tals judicis per abastar alguns aspectes centrals de la nostra concepció del món, com ara els nostres judicis estètics i axiològics. Estén, per tant, als problemes de la raó pràctica l'argument transcendental que Kant va confinar als judicis de les ciències naturals.

La qüestió filosòfica que alimenta les reflexions de Stroud en aquestes conferències (i en tota la seua obra, com hem vist) és la d'entendre "la relació que mantenim nosaltres i la nostra concepció del món amb el món en si mateix". El subjectivisme ens proposa una resposta a aquesta pregunta pel que fa a alguns aspectes fonamentals, com són els judicis estètics i axiològics. Aquesta resposta pressuposa una imatge de la nostra concepció del món com a fruit de la combinació del que aporta el món i el que posem nosaltres. Aquesta imatge ens obliga a entendre el que posem nosaltres com quelcom aillat del món, i aquesta és la lectura restringida de l'experiència de la qual Hume aspira a derivar el contingut de totes les nostres idees. És aquesta una estratègia de baix cap amunt que, segons hem vist, no pot concebre's coherentment. Kant ens proposa l'estratègia contrària, de dalt cap avall. Descriguem, primer, el contingut de les nostres creences, els nostres sentiments i les nostres experiències i vegem, després, com han pogut originar-se. S'esdevé, però, que les nostres creences estètiques i axiològiques no es poden entendre sense suposar que en el món objectiu hi ha propietats d'aquesta mena, per la qual cosa ens veiem obligats a rebutjar no sols el tractament subjectivista de les creences estètiques $\mathrm{i}$ morals, sinó també la lectura restringida de l'experiència i la imatge de la nostra concepció del món a la qual s’associa. Una vegada concedim que no podem entendre el nostre lloc al món en què creiem sense entendre l'experiència d'una manera enriquida, impregnada de conceptes i de judicis, també hem d'acceptar que la pregunta filosòfica sobre la relació entre la nostra concepció del món i el món en què creiem s'ha d'elaborar en termes molt més circulars del que podríem esperar i desitjar. 